Article

\title{
Research on Influential Mechanism of HAZ Impact Toughness for Shipbuilding Steel with Mg Addition
}

\author{
Hui-rong Li, Li-gen Sun *, Li-guang Zhu, Yun-song Liu and Yun-gang Li \\ College of Metallurgy and Energy, North China University of Science and Technology, Tangshan 063210, China; \\ lihuirong@ncst.edu.cn (H.-r.L.); zhulg@ncst.edu.cn (L.-g.Z.); pandalys@163.com (Y.-s.L.); \\ lyg@ncst.edu.cn (Y.-g.L.) \\ * Correspondence: sunligen1983@outlook.com; Tel.: +86-13315568791
}

Received: 30 June 2018; Accepted: 24 July 2018; Published: 26 July 2018

\begin{abstract}
The welding performance of shipbuilding steel under large heat input could be improved greatly by the addition of $\mathrm{Mg}$ to the steel, but the impact toughness of the heat affect zone (HAZ) is not stable. According to the three different thickness steel plates obtained in the industrial experiment, the large heat input welding was carried out by different heat input, and the impact toughness analysis, impact fracture analysis, metallographic microstructure analysis and inclusions analysis were carried out. The results showed that, the HAZ of three kinds of thickness plates induced much intragranular acicular ferrite (IAF); with $\mathrm{Mg}$ addition, the inclusion dimension had been reduced effectively, and the IAF-induced ability of the inclusions had also been improved. The difference of HAZ impact toughness with different welding heat input and different impact temperature is significant; considering the influence of welding heat input and metallographic microstructure on the impact toughness of HAZ, the welding heat load had a far greater effect than the metallographic microstructure on ductile-brittle transition temperature. At the same time, if the original metallographic microstructure of steel was coarse, the pinning effect of the inclusions would be reduced significantly, and the microstructure of HAZ would be coarsened and the impact toughness of HAZ would be decreased, so there is a certain matching relationship between the metallographic microstructure and the inclusion dimension.
\end{abstract}

Keywords: oxide metallurgy; impact toughness; metallographic structure; inclusion; ductile-brittle transition temperature

\section{Introduction}

In recent years, the shipbuilding industry has developed rapidly, especially in eastern Asia. In order to further shorten the shipbuilding time and improve competitive power, high-efficiency large heat input welding technology has been brought into the industry. The upgrade of welding technology put forward new requirements for the ship structural steel, that is, the shipbuilding steel must have higher strength and higher toughness, and must also have good high heat input weldability. The so-called high heat input welding refers to the welding line energy $\geq 50 \mathrm{~kJ} / \mathrm{cm}$, and it is an efficient welding method. Under the high input energy of the welding line, the traditional HAZ (heat affect zone) of the shipbuilding steel would undergo severe grain coarsening, localized softening and embrittlement, and result in a significant reduction in impact toughness and a serious threat to the safety of the ship structure.

In order to improve the impact toughness of the HAZ, J. Takamura and S. Mizoguchi [1,2], for the first time, worked in Nippon Steel and proposed the application of oxide metallurgy technology to the development of shipbuilding steel for high heat input welding. According to J. Takamura and S. Mizoguchi, a large number of finely dispersed inclusions in the steel pinned prior austenite 
grains to prevent their growth; on the other hand, they could induce IAF (intragranular acicular ferrite), and further refine the intragranular structure. Around this type of inclusion with double grain refinement effect, particularly the ability to induce IAF, many scholars have carried out much research work. Hitoshi H [3] and Shu Wei [4] found that TiOx and MnS composite inclusions can effectively induce the IAF, and the size of such inclusions is generally less than $3 \mu \mathrm{m}$ [5]. However, the induction effect of TiOx is not stable, because it tends to agglomerate and grow, and is difficult to realize distribution diffusely; the coarse TiOx inclusions could also be the source of steel cracks. Vega M I [6] and S. Kanazawa [7] believed that TiN could effectively induce IAF and was not easily condensed. However, Kasamatsu Y [8] found that when the temperature exceeds $1350{ }^{\circ} \mathrm{C}$, TiN would partially solid-solubilize, the amount of TiN will drop sharply after cooling and precipitation, and then lead to a significant decrease in its inducing ability. Therefore, this method limits the input line energy during welding. In order to obtain dispersed and stable Ti-containing inclusions, scholars began to add microalloying elements such as $\mathrm{Mg}$ (Ca) to the steel [9-11]. At present, the development of this $\mathrm{Mg}$-based shipbuilding steel is at the forefront of the research and application of oxide metallurgy theory and technology.

As the representative parameters of comprehensive mechanical properties of shipbuilding steel, impact toughness influence factors include steel composition, rolling process, heat treatment process, metallurgical composition and impact test temperature [12-15]. For the heat affected zone of Mg-based shipbuilding steel involved in this study, the main influencing factors are the grain coarsening caused by welding heat load and the corresponding impact test temperature.

In this study, corresponding large heat input welding and impact tests at different temperatures were carried out for steel plates with different thicknesses. At the same time, the morphology of the impact fractures, microstructures, and the presence of inclusions were systematically studied, to obtain of the impact toughness influence mechanism of HAZ for Mg-based shipbuilding steel, an effective way to improve the energy weldability of shipbuilding steel would also be explored.

\section{Materials and Methods}

The Mg-based shipbuilding steels used in the experiments were trial-produced in a real steel plant. The chemical composition is shown in Table 1 . The steel was molten by $120 \mathrm{t}$ converter, refined by LF (Ladle Furnace) where the Mg had been added into by the sustained release Mg Line, and cast by the slab continuous casting machine with the cross section $210 \mathrm{~mm} \times 1800 \mathrm{~mm}$. For the rolling process, TMCP (Thermo Mechanical Control Process) technology had been used, and the slabs were rolled into three thickness plates of $16 \mathrm{~mm}, 25 \mathrm{~mm}$ and $40 \mathrm{~mm}$, respectively, and the three types of steel plates were from the same heat. The initial rolling temperature was $1050-1120^{\circ} \mathrm{C}$, and the final rolling temperature was controlled at $890-830^{\circ} \mathrm{C}$. The dimensions of the three kinds of plates for welding were different, for $16 \mathrm{~mm}$ thickness plates, the dimension was $800 \mathrm{~mm} \times 250 \mathrm{~mm} \times 16 \mathrm{~mm}$, for $25 \mathrm{~mm}$ thickness plates, the dimension was $1000 \mathrm{~mm} \times 300 \mathrm{~mm} \times 25 \mathrm{~mm}$, and for $40 \mathrm{~mm}$ thickness plates, the dimension was $1200 \mathrm{~mm} \times 400 \mathrm{~mm} \times 40 \mathrm{~mm}$.

Table 1. The chemical composition of the steel trial (mass $\%$ ).

\begin{tabular}{cccccccccccc}
\hline Composition & $\mathbf{C}$ & $\mathbf{S i}$ & $\mathbf{M n}$ & $\mathbf{S}$ & $\mathbf{P}$ & $\mathbf{A l}$ & $\mathbf{T i}$ & $\mathbf{M o}$ & $\mathbf{V}$ & $\mathbf{N b}$ & $\mathbf{M g}$ \\
\hline content & 0.08 & 0.20 & 1.40 & 0.005 & 0.015 & 0.01 & 0.015 & 0.07 & 0.04 & 0.04 & 0.005 \\
\hline
\end{tabular}

The yield strengths of the three-thickness steel plates all exceeded $460 \mathrm{MPa}$, and the tensile strengths exceeded $520 \mathrm{MPA}$, the elongations of $40 \mathrm{~mm}$-thick steel plate exceeded $23 \%$, and for the other two exceeded $32 \%$, the cold bending performance of the three was also up to standard. For impact work at $-20{ }^{\circ} \mathrm{C}$, three thicknesses of steel plate exceeded $230 \mathrm{~J}$, and $25 \mathrm{~mm}$ thick steel plate exceeded $300 \mathrm{~J}$, which greatly exceeded the requirements of classification society (CCS) for EH36 plate steel. 
For the large heat input welding technique, the thicker the steel base material, the higher the required welding line energy. In order to ensure that the steel plates were welded together and the melting of the steel plate caused by excessive line energy was avoided at the same time, various input line energies had been tested for the three thickness steel plates, and the final determination was that, the $16 \mathrm{~mm}$ thick steel plate adopted $50 \mathrm{~kJ} / \mathrm{cm}$ input line energy, $25 \mathrm{~mm}$ thick steel plate adopted $100 \mathrm{~kJ} / \mathrm{cm}$ input line energy, and the $40 \mathrm{~mm}$ thick steel plate adopted $150 \mathrm{~kJ} / \mathrm{cm} 1$ input line energy. The specific welding parameters and wire material are shown in Table 2, in which the $16 \mathrm{~mm}$ thick steel plates were welded by monofilament submerged arc welding, and the 25 and $40 \mathrm{~mm}$ thick steel plates were welded by double wire submerged arc welding, the welding heat input was calculated by Equation (1). The welding method was flat V-groove butt welding.

$$
q=\frac{I U}{v}
$$

where $q$-heat input, $\mathrm{J} / \mathrm{cm}$,

I-welding current, A,

$U$-welding voltage, $\mathrm{V}$,

v—welding speed, $\mathrm{cm} / \mathrm{s}$.

Table 2. Welding parameters.

\begin{tabular}{|c|c|c|c|c|c|c|c|c|}
\hline \multirow{3}{*}{$\begin{array}{l}\text { Thickness } \\
\text { (mm) }\end{array}$} & \multirow{3}{*}{$\begin{array}{l}\text { Input Line Energy } \\
(\mathrm{KJ} / \mathrm{cm})\end{array}$} & \multirow{3}{*}{$\begin{array}{l}\text { Welding } \\
\text { Speed }(\mathrm{m} / \mathrm{h})\end{array}$} & \multirow{3}{*}{$\begin{array}{l}\text { Welding Wire } \\
\text { Diameter (mm) }\end{array}$} & \multirow{3}{*}{$\begin{array}{l}\text { Welding Wire } \\
\text { Kinds }\end{array}$} & \multicolumn{2}{|c|}{ Fore Wire } & \multicolumn{2}{|c|}{ Hind Wire } \\
\hline & & & & & Current & Voltage & Current & Voltage \\
\hline & & & & & (A) & (V) & (A) & (V) \\
\hline 16 & 50 & 19.6 & 4.0 & $10 \mathrm{Mn} 2$ & 780 & 35 & & \\
\hline 25 & 100 & 24 & $5.0+5.0$ & $10 \mathrm{Mn} 2+\mathrm{SJ} 501$ & 1000 & 41 & 700 & 37 \\
\hline 40 & 150 & 22.7 & $5.0+5.0$ & $10 \mathrm{Mn} 2+\mathrm{SJ} 501$ & 1200 & 44 & 1000 & 42 \\
\hline
\end{tabular}

After the welding, the impact specimen had been prepared by wire cut. For each plate, according to GB/T 229-2007, the dimension of the impact sample was $10 \mathrm{~mm} \times 10 \mathrm{~mm} \times 60 \mathrm{~mm}$, the position $2 \mathrm{~mm}$ that from the fusion line was selected to be tested for the impact toughness of the weld heat affected zone. The impact temperatures were $-20^{\circ} \mathrm{C}$ and $-40^{\circ} \mathrm{C}$. Three test specimens were selected for impact test at each test temperature. The final results were averaged, and the total number of test specimens was 18.

After the impact test, the fracture surface morphology, metallographic structure and inclusions of the impact specimen were analyzed by using stereomicroscope, optical microscope, scanning electron microscope and energy spectrum.

\section{Results}

\subsection{Impact Testing}

Table 3 shows the results of impact toughness of the welding heat affected zone with different thicknesses at $-20^{\circ} \mathrm{C}$ and $-40{ }^{\circ} \mathrm{C}$.

Table 3. Impact results.

\begin{tabular}{ccccccc}
\hline Thickness/mm & $\begin{array}{c}\text { Input Line } \\
\text { Energy/kJ/cm }\end{array}$ & $\begin{array}{c}\text { Impact } \\
\text { Temperature/ }\end{array}{ }^{\circ} \mathbf{C}$ & \multicolumn{2}{c}{ Impact Absorbed Energy/J } & Averaged Value/J \\
\hline \multirow{2}{*}{16} & \multirow{2}{*}{50} & -20 & 197.3 & 166.7 & 172.0 & 178.7 \\
& \multirow{2}{*}{25} & -40 & 89.6 & 49.0 & 74.3 & 71.0 \\
\hline \multirow{2}{*}{100} & -20 & 42.5 & 91.4 & 38.6 & 57.5 \\
& \multirow{2}{*}{40} & -40 & 51.8 & 30.2 & 17.4 & 33.1 \\
\hline \multirow{2}{*}{150} & -20 & 198.9 & 189.5 & 197.6 & 195.3 \\
& & -40 & 32.9 & 35.7 & 27.5 & 32.0 \\
\hline
\end{tabular}


From the test results in Table 3 , it shows that, at $-20{ }^{\circ} \mathrm{C}, 16 \mathrm{~mm}$ thickness steel plate and $40 \mathrm{~mm}$ thickness steel plate had better impact toughness values in the heat-affected zone under the corresponding high heat input welding conditions, especially for $40 \mathrm{~mm}$ thickness steel plate. The average impact energy had reached $195.3 \mathrm{~J}$; while the $25 \mathrm{~mm}$ steel plate under $100 \mathrm{~kJ} / \mathrm{cm}$ line energy welding, the corresponding average impact energy value is only $57.5 \mathrm{~J}$, which is relatively low.

When the test temperature is lowered from $-20{ }^{\circ} \mathrm{C}$ to $-40{ }^{\circ} \mathrm{C}$, the impact energy values of the three were greatly reduced, the impact energy value of HAZ for the $16 \mathrm{~mm}$ thickness steel plate is $71 \mathrm{~J}$, and the $25 \mathrm{~mm}$ and $40 \mathrm{~mm}$ were only $33.1 \mathrm{~J}$ and $32 \mathrm{~J}$, respectively. Although the values had reached the national standard requirements, they were nonetheless very low.

\subsection{Impact Fracture}

\subsubsection{Macroscopic Feature}

The macroscopic fracture morphologies of impact fracture for different thickness at different temperatures were observed under a 50-fold microscope, and the typical morphology of impact fractures at $-20{ }^{\circ} \mathrm{C}$ are shown in Figure 1, the typical morphology of impact fractures at $-40{ }^{\circ} \mathrm{C}$ are shown in Figure 2.

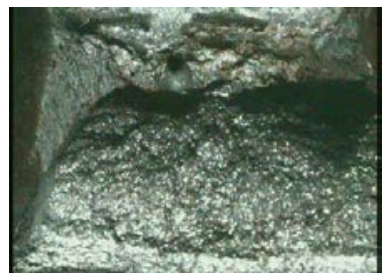

(a)

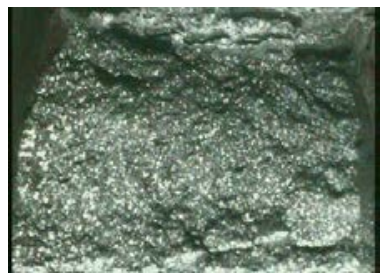

(b)

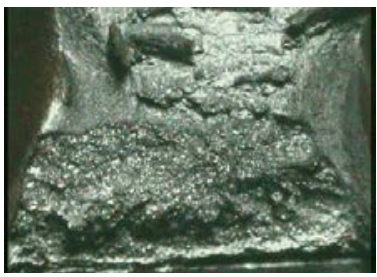

(c)

Figure 1. Macroscopic fracture $\left(-20{ }^{\circ} \mathrm{C}\right)$ : (a), impact fracture of $16 \mathrm{~mm}$ thickness plate; (b), impact fracture of $25 \mathrm{~mm}$ thickness plate; (c), impact fracture of $40 \mathrm{~mm}$ thickness plate.

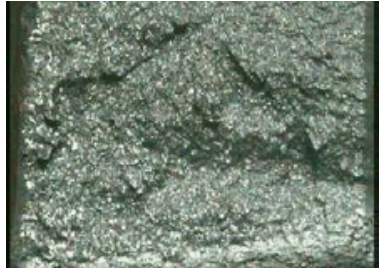

(a)

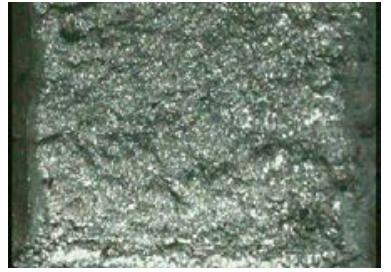

(b)

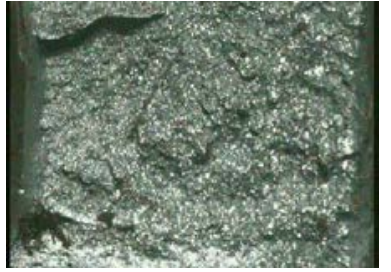

(c)

Figure 2. Macroscopic fracture $\left(-40{ }^{\circ} \mathrm{C}\right)$ : (a), impact fracture of $16 \mathrm{~mm}$ thickness plate; (b), impact fracture of $25 \mathrm{~mm}$ thickness plate; (c), impact fracture of $40 \mathrm{~mm}$ thickness plate.

As shown in Figures 1 and 2, the impact section structures of the HAZ for the three-thickness steel plate at $-20^{\circ} \mathrm{C}$ were much better than these at $-40{ }^{\circ} \mathrm{C}$. At $-20^{\circ} \mathrm{C}$, the common feature of the three typical impact fractures was that the impact specimen had a large number of deep elongated shear lips near the narrow part of the V-groove area [16], and it appeared farther away from the impact V-groove, with obvious fibrous, fractured areas filled with relatively sharp tear edges, which indicated that the impact toughness of the $\mathrm{HAZ}$ is better at $-20^{\circ} \mathrm{C}$. For comparison, the ratio of the long shear lip in the fracture of the $25 \mathrm{~mm}$ steel plate was relatively low, and the impact absorbed energy was also significantly lower than the other two.

Compared with the above, the three typical impact fractures in Figure $2 a-c$ were relatively flat, with a large number of small facets, radial and herringbone stripes, and there was no obvious tearing edge. 


\subsubsection{Microscopic Feature}

The impact fracture specimen was sampled by wire cut at a distance of $10 \mathrm{~mm}$ from the fracture surface. The sample was cleaned with an ultrasonic cleaner, then wiped with alcohol, dried, and finally placed in a scanning electron microscope to observe the microscopic appearance of the fracture. The typical microscopic morphology of impact fractures for different plate thicknesses at $-20{ }^{\circ} \mathrm{C}$ are shown in Figure 3, and the typical microscopic morphology of impact fractures for different plate thicknesses at $-40^{\circ} \mathrm{C}$ are shown in Figure 4 .

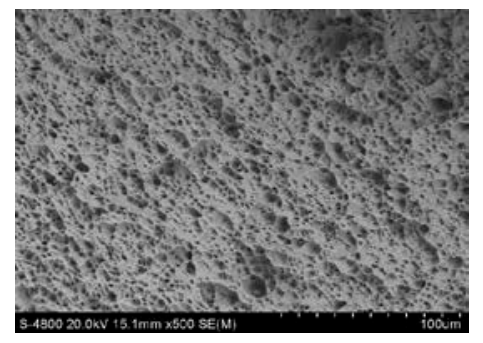

(a)

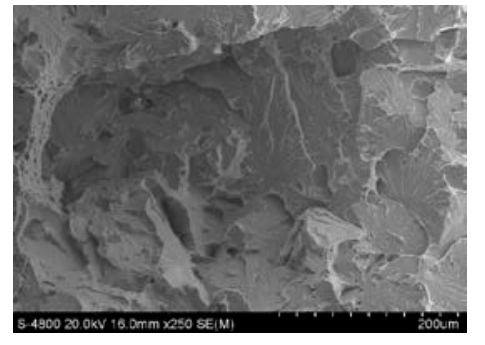

(b)

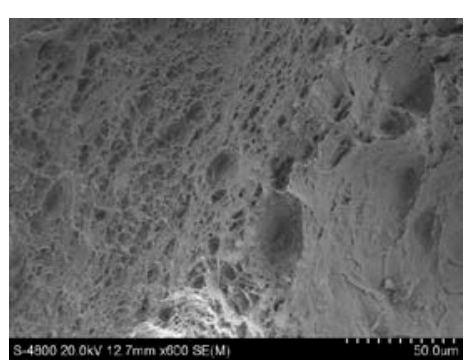

(c)

Figure 3. Sample of micro-fracture $\left(-20^{\circ} \mathrm{C}\right)$ : (a), impact fracture of $16 \mathrm{~mm}$ thickness plate; (b), impact fracture of $25 \mathrm{~mm}$ thickness plate; (c), impact fracture of $40 \mathrm{~mm}$ thickness plate.

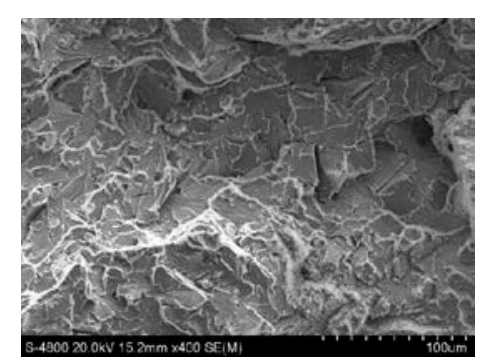

(a)

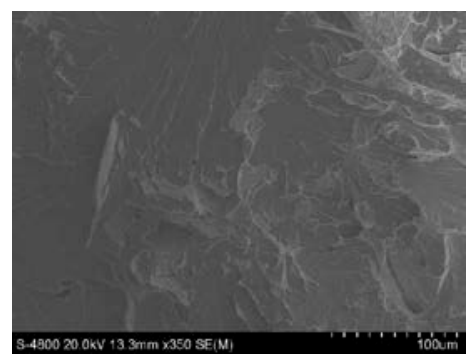

(b)

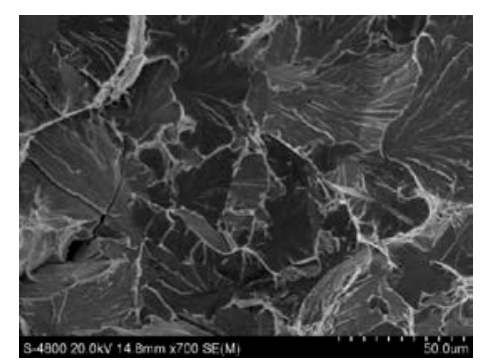

(c)

Figure 4. Sample of micro-fracture $\left(-40^{\circ} \mathrm{C}\right)$ : (a), impact fracture of $16 \mathrm{~mm}$ thickness plate; (b), impact fracture of $25 \mathrm{~mm}$ thickness plate; (c), impact fracture of $40 \mathrm{~mm}$ thickness plate.

Typical micrographs of impact fractures in the heat affected zone of steel plates thickness $16 \mathrm{~mm}$, $25 \mathrm{~mm}$, and $40 \mathrm{~mm}$ at $-20{ }^{\circ} \mathrm{C}$ are shown in Figure $3 \mathrm{a}-\mathrm{c}$, and the impact absorbed values were 197.3 J, $42.5 \mathrm{~J}$, and 197.6 J, respectively. Among them, the fracture micro-morphology shown in Figure 3a was a dense and unequal equiaxed dimple formed by tensile pulling force, and there was a phenomenon of enrichment of small dimples near the large dimple, and it was the typical ductile fractures; as shown in Figure $3 b$, the microscopic morphology of the fractures was as a fan-shaped cleavage pattern, in which there were distinct torn edges, and there were very few small and shallow dimples in some regions, and there were also solutions in the entire section. Columns are typical quasi-cleavage fractures; the fractures shown in Figure 3c were composed of sheared elongated dimples and partially shallow and small equiaxed dimples, in which elongated dimples had a certain direction. The reason for the above is that the sample was punctured and ruptured under the impact of an impact force and was a typical ductile fracture. For the perspective of the fracture mechanism, the microscopic morphologies of the three types of fractures were consistent with the corresponding impact energy values [16-18].

Figure $4 \mathrm{a}-\mathrm{c}$ show the typical microscopic appearances of impact fractures in the HAZ of steel plate thicknesses of $16 \mathrm{~mm}, 25 \mathrm{~mm}$ and $40 \mathrm{~mm}$ at $-40{ }^{\circ} \mathrm{C}$, respectively, under the corresponding energy welding conditions. The corresponding impact absorbed values were $49.0 \mathrm{~J}, 17.4 \mathrm{~J}$ and 35.7 J, respectively. Among them, Figure 4a shows that the uneven dimples appeared in the micro-morphology of the fracture surface, and also that there were some smaller cleavage surfaces, 
and clearer tearing edges, which were typical characters of the quasi-cleavage fracture; Figure $4 \mathrm{~b}$ shows that the micro-morphology of the fracture was mainly a river pattern. During the process of extending from the cleavage crack outward to the crystal phase, a large number of steps gather and the direction of the river flow were consistent with the direction in which the crack extends outward. The brittle fractures of Figure $4 \mathrm{c}$ shows fracture features resembling "fans" at the fractures, which were mainly due to cleavage cracks originating in the crystal near the grain boundary, and the river pattern would be in the form of a fan to extend outwards, and these were the typical quasi-cleavage fracture [16-18].

Figure $4 \mathrm{a}-\mathrm{c}$ show the typical microscopic appearances of impact fractures in the HAZ of steel plate thicknesses of $16 \mathrm{~mm}, 25 \mathrm{~mm}$ and $40 \mathrm{~mm}$ at $-40{ }^{\circ} \mathrm{C}$, respectively, under the corresponding energy welding conditions. The corresponding impact absorbed values were $49.0 \mathrm{~J}, 17.4 \mathrm{~J}$ and $35.7 \mathrm{~J}$, respectively. Among them, Figure 4a shows that the uneven dimples appeared in the micro-morphology of the fracture surface, and also that there were some smaller cleavage surfaces, and clearer tearing edges, which were typical characters of the quasi-cleavage fracture; Figure $4 \mathrm{~b}$ shows that the micro-morphology of the fracture was mainly a river pattern. During the process of extending from the cleavage crack outward to the crystal phase, a large number of steps gather and the direction of the river flow were consistent with the direction in which the crack extends outward. The brittle fractures of Figure 4c shows fracture features resembling "fans" at the fractures, which were mainly due to cleavage cracks originating in the crystal near the grain boundary, and the river pattern would be in the form of a fan to extend outwards, and these were the typical quasi-cleavage fracture [16-18].

As shown in the experimental results, it can be seen that both the macroscopic appearance and the microscopic appearance of the fracture were matched with the corresponding impact absorbed energy values, and there was no sharp drop in the impact absorbed energy value caused by the steel plate defect, which indicated that the impact energy value could completely represent the impact toughness of the HAZ of the steel plate under the corresponding welding and impact conditions.

\section{Discussion}

\subsection{Influence of Welding Heat Input}

For normal conditions, the welding line energy characterizes the heat input per welding area, but for different thickness steel plates, the heat load in the local area does not necessarily increase with the increase of weld heat input, it also depends on the steel plate thickness. For this reason, the welding heat load of three kinds of steel plates had been calculated. The results are shown in Figure 5. From Figure 5, it could be seen that the $25 \mathrm{~mm}$ thickness steel plate had the highest heat load, reaching $0.40 \mathrm{~kJ} / \mathrm{mm}^{2}$, which would exacerbate the tendency to deteriorate the microstructure of the heat-affected zone, which may be one of the causes for its lower impact toughness. Although the thermal load of the $40 \mathrm{~mm}$ thickness steel plate had reached $0.38 \mathrm{~kJ} / \mathrm{mm}^{2}$, the impact on the impact test results was relatively small.

At $-40^{\circ} \mathrm{C}$, the impact absorbed energy values of the three were greatly reduced, especially for the $40 \mathrm{~mm}$ thickness steel plate, and correspondingly, the impact energy value reduced $163.3 \mathrm{~J}$, even lower than the corresponding value of the $25 \mathrm{~mm}$ thickness steel plate, which was $32.0 \mathrm{~J}$. The impact energy value of the $16 \mathrm{~mm}$ thickness steel plate was $71 \mathrm{~J}$, more than twice that of the other two. The key factor that causes this result was the ductile-brittle transition temperature of the test steel.

The ductile-brittle transition temperature of steel is influenced by factors such as thermal processing [19,20], metallurgical composition [21], and grain boundary precipitation [22]. For this research, the metallographic structure properties and heat load were closely related in the welding process [23]. From Figure 5, it could be seen that the corresponding heat load of the $16 \mathrm{~mm}$ thickness steel plate was significantly lower than the other two, and the impact energy value at the $-40{ }^{\circ} \mathrm{C}$ corresponding to the HAZ was $71 \mathrm{~J}$, which was obviously higher than that of the other two also. It is shown that the welding heat input had a great influence on the ductile-brittle transition temperature of the steel. 


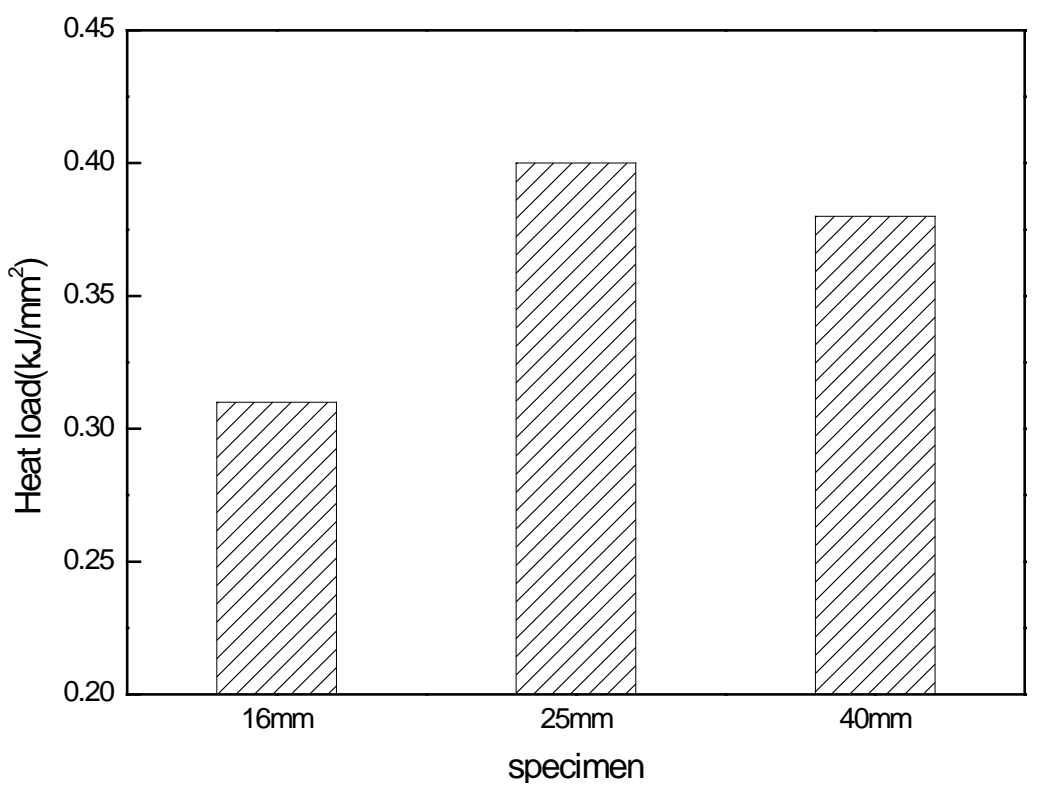

Figure 5. Welding heat load.

In theory, the cooling rate has a greater impact on the microstructure [24,25]. With the increase of the thickness of the steel plate, under the same external cooling conditions, the greater the thickness of the steel plate, the lower the overall cooling rate. Moreover, the heat loads of $25 \mathrm{~mm}$ and $40 \mathrm{~mm}$ thickness steel plates were all higher than those of $16 \mathrm{~mm}$, so the impact of welding heat input on impact toughness of $25 \mathrm{~mm}$ and $40 \mathrm{~mm}$ thick steel plates, especially the impact on the ductile-brittle transition temperature, was significantly higher than that of the $16 \mathrm{~mm}$ thick steel plates. However, at the same time, at $-20{ }^{\circ} \mathrm{C}$, without considering the influence of the ductile-brittle transition temperature of the test steel, the impact toughness of $40 \mathrm{~mm}$ thickness steel plate was much higher than that of $25 \mathrm{~mm}$, so the metallographic structures of the three thickness steel plates should be analyzed further.

\subsection{Analysis of Metallographic Structures}

The metallographic structure of $16 \mathrm{~mm}$ thickness steel plate with welding heat input $50 \mathrm{~kJ} / \mathrm{cm}$ under 100-fold field of view are shown in Figure $6 a-d$, and the higher magnification image of partial area of Figure $6 \mathrm{~b}$ is shown in Figure 6e. Figure $6 \mathrm{a}$ is the welding fusion zone, Figure $6 \mathrm{~b}, \mathrm{c}$ are the welding heat affected zone, and Figure $6 \mathrm{~d}$ is the metallographic structure of the steel plate.

As shown in Figure 6a, the metallographic structure of the HAZ in the right half of the weld line was a little thicker, which was approximately $100 \mu \mathrm{m}$ away from the weld line, but with the distance increasing, the structure became finer. Combining with the metallographic structures of the two welding heat affected zones in Figure 6b,c, especially in Figure 6e, it could be found that the overall HAZ structure was relatively uniform, and due to the appearance of a large number of IAF, The austenite grain in the heat-affected zone had been effectively fined. For the entire weld heat affected zone, the nearer to the weld line, the higher the rate of IAF in the metallurgical structure. Under the condition that a large amount of IAF was induced, the heat affected zone was even more fine and uniform than the original plate (as shown in Figure 6d). 


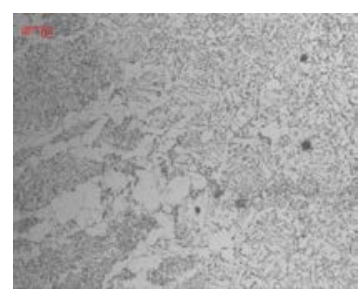

(a)

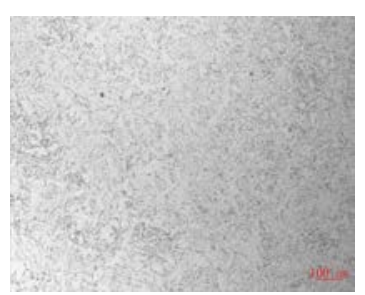

(b)

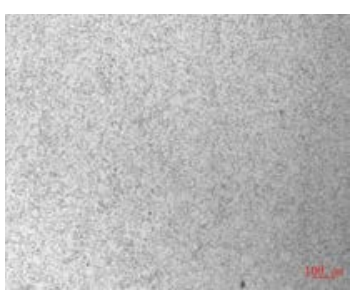

(c)

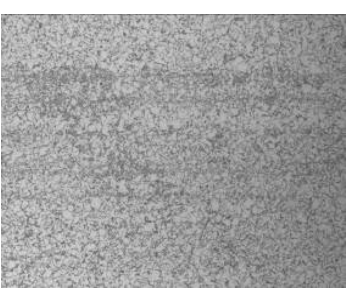

(d)

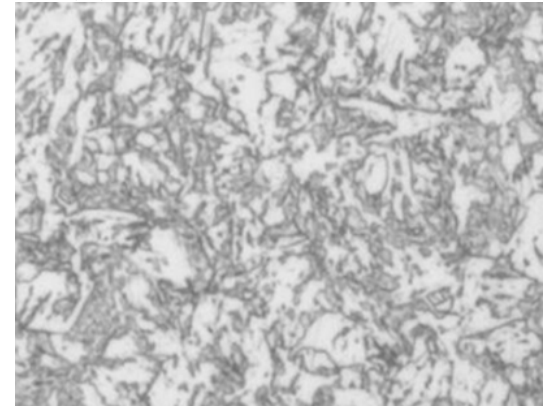

(e)

Figure 6. Metallographic structure of HAZ for $16 \mathrm{~mm}$ thickness: (a), the metallographic structure of welding fusion zone; $(\mathbf{b}, \mathbf{c})$, the metallographic structure of welding heat affected zone; $(\mathbf{d})$, the metallographic structure of the steel plate; (e), the higher magnification image of partial area of Figure $6 \mathrm{~b}$.

The metallographic structure of $25 \mathrm{~mm}$ thickness steel plate with welding heat input $100 \mathrm{~kJ} / \mathrm{cm}$ under 100-fold field of view are shown in Figure 7a-d, and the higher magnification image of partial area of Figure $7 \mathrm{~b}$ is shown in Figure $7 \mathrm{e}$. Figure $7 \mathrm{a}$ is the welding fusion zone, Figure $7 \mathrm{~b}, \mathrm{c}$ are the welding heat affected zone, and Figure $7 \mathrm{~d}$ is the metallographic structure of the steel plate.

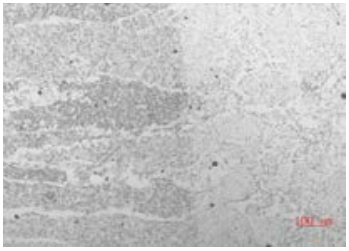

(a)

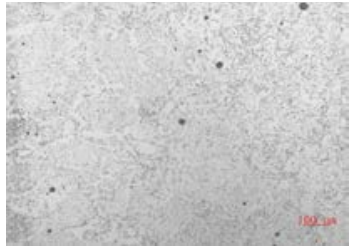

(b)

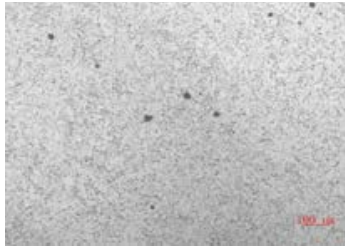

(c)

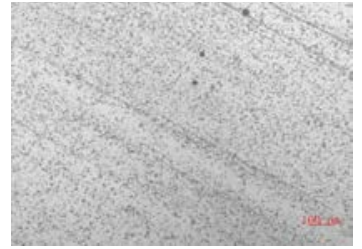

(d)

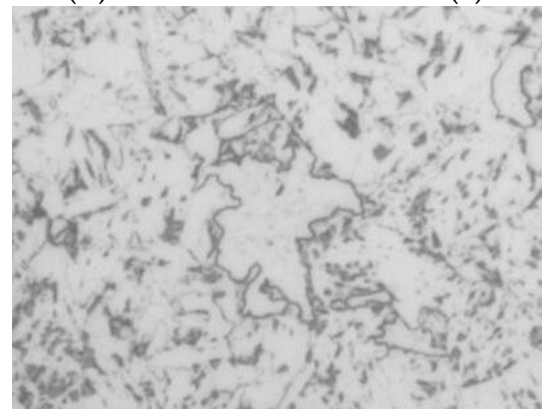

(e)

Figure 7. Metallographic structure of HAZ for $25 \mathrm{~mm}$ thickness: (a), the metallographic structure of welding fusion zone; $(\mathbf{b}, \mathbf{c})$, the metallographic structure of welding heat affected zone; $(\mathbf{d})$, the metallographic structure of the steel plate; (e), the higher magnification image of partial area of Figure $7 \mathrm{~b}$.

As shown in Figure 7a, the metallographic structure of the right side of the fusion line was significantly coarsened. The metallographic structure of the HAZ showed in Figure $7 \mathrm{~b}$ was closer to the weld fusion line; it is shown that, the metallographic structure in the lower left area was significantly 
coarser than that of the upper right area, and the microstructure in the upper right area was the same as the metallographic structure shown in Figure 7c,e than the higher magnification images. This showed that, due to the larger heat load of the $25 \mathrm{~mm}$ thickness steel plate, the metallographic structure was obviously coarsened. However, due to the induction of IAF, which had effectively restricted the coarsening of the microstructure, the roughening of the most of the heat-affected zones was not as serious as compared with the steel plate. This is the reason that the impact toughness value of the $25 \mathrm{~mm}$ thickness steel plate could reach twice that of the national standard.

The metallographic structure of $40 \mathrm{~mm}$ thickness steel plate with welding heat input $150 \mathrm{~kJ} / \mathrm{cm}$ under 100-fold field of view are shown in Figure 8a-d, and the higher magnification image of partial area of Figure $8 b$ is shown in Figure $8 e$. Figure $8 a$ is the welding fusion zone, Figure $8 b, c$ are the welding heat affected zone, and Figure $8 \mathrm{~d}$ is the metallographic structure of the steel plate.

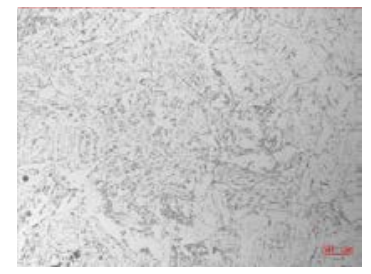

(a)

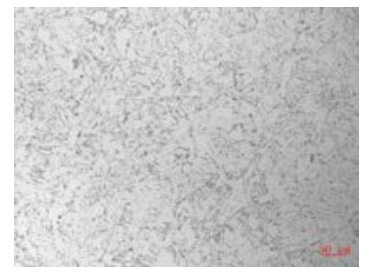

(b)

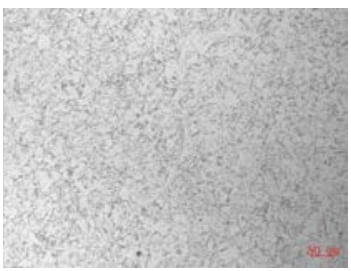

(c)

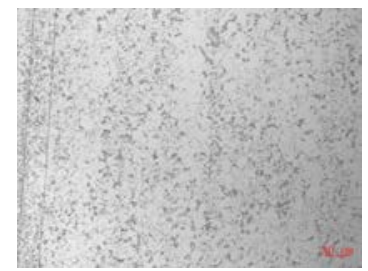

(d)

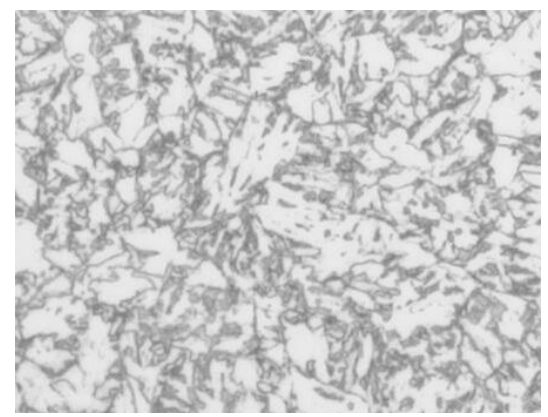

(e)

Figure 8. Metallographic structure of HAZ for $40 \mathrm{~mm}$ thickness: (a), the metallographic structure of welding fusion zone; $(\mathbf{b}, \mathbf{c})$, the metallographic structure of welding heat affected zone; $(\mathbf{d})$, the metallographic structure of the steel plate; (e), the higher magnification image of partial area of Figure $8 \mathrm{~b}$.

At $-20^{\circ} \mathrm{C}$, the HAZ impact toughness of $40 \mathrm{~mm}$ thickness steel plate was similar to $16 \mathrm{~mm}$ thickness steel plate, as shown in Figure $8 \mathrm{a}-\mathrm{d}$, the metallographic structure was also the same as the corresponding area of the $16 \mathrm{~mm}$ thickness steel plate. With a large amount of IAF inducing, the metallographic structure of HAZ was not only no coarser, but also even more uniform and finer than the steel plate.

For the above analysis, it could be seen that the welding heat load of a $25 \mathrm{~mm}$ thickness steel plate was not much different from $40 \mathrm{~mm}$ thickness steel plate, but the impact toughness value was significantly lower than the $40 \mathrm{~mm}$ thickness steel plate. As shown in Figures $7 \mathrm{~d}$ and $8 \mathrm{~d}$, the microstructures of $25 \mathrm{~mm}$ thickness steel plate were significantly thicker than that of the $40 \mathrm{~mm}$ thickness steel plate, and the corresponding welded heat affected zone also showed the same phenomenon. Due to the coarseness of the original structure of the steel plate, the microstructure of the welding heat affected zone is severely roughened, which indicates that the resistance of the coarse structure to the weld line energy is far worse than that of the fine structure. This also leads to the reduction of the impact toughness of the welded heat affected zone of the $25 \mathrm{~mm}$ thickness steel plate. The above analysis indicates that the TMCP process used to roll the $25 \mathrm{~mm}$ thick steel plates in actual production needs further optimization. 
At $-40{ }^{\circ} \mathrm{C}$, the metallographic structure of the weld heat affected zone did not change, but the corresponding impact toughness value of the $40 \mathrm{~mm}$ thickness steel plate decreased drastically; that indicated that the ductile brittle transition temperature of the test steel was not directly related to the thickness of the metallographic structure. Shen Dongdong et al [26] have also obtained similar results.

Through the above metallographic analysis, it could be found that the metallographic structure of the HAZ of the $16 \mathrm{~mm}$ and $40 \mathrm{~mm}$ thickness steel plates was even finer than that of the original steel plate. The HAZ metallographic structure of the $25 \mathrm{~mm}$ thickness steel plate was coarser than the original steel plate. That was attributed to the induction of the amount of IAF in the HAZ. Therefore, it is necessary to do further analysis about the inclusions which induced the IAF.

\subsection{Analysis of Inclusions}

For oxide metallurgical steels, the inclusions could pin the austenite grains to prevent growing, and could also induce the IAF in the austenite grains to make the grain finer. Therefore, for the HAZ with the three different thicknesses steel plates, the number of micro-inclusions had been statistically graded in this study $[27,28]$, and the results are shown in Table 4 .

Table 4. Statistical result of micro-inclusions in different HAZ.

\begin{tabular}{ccccc}
\hline Thickness of Steel Plate & $\mathbf{0 - 5} \boldsymbol{\mu m}$ & $\mathbf{5 - 1 0} \boldsymbol{\mu m}$ & $\mathbf{1 0 - 1 5} \boldsymbol{\mu m}$ & $\mathbf{1 5 - 2 0} \boldsymbol{\mu m}$ \\
\hline $16 \mathbf{m m}$ & 83 & 14 & 16 & 14 \\
$25 \mathrm{~mm}$ & 100 & 20 & 8 & 2 \\
$40 \mathrm{~mm}$ & 67 & 26 & 6 & 10 \\
\hline
\end{tabular}

As shown in Table 4, the inclusion size of the HAZ was mainly in the range of $0-5 \mu \mathrm{m}$. These types of oxides could be the nuclear core for IAF inducing and play the pinning effect to restrict austenite grains growing. In comparison, for the range of $0-5 \mu \mathrm{m}$, the maximum number of inclusions in the heat affected zone of the $25 \mathrm{~mm}$ thick steel plate was the largest, but the IAF rate of the $25 \mathrm{~mm}$ thickness steel plate was relatively low; this may be due to the relative thicker metallographic structure for the $25 \mathrm{~mm}$ thickness of the original steel plate.

For further research, the oxides size for the shipbuilding steel with $\mathrm{Mg}$ and normal shipbuilding steel without $\mathrm{Mg}$ had been counted by the Aspex, the results are shown in Table 5.

Table 5. Partial test results of automatic scanning system for Micro-inclusions.

\begin{tabular}{|c|c|c|c|c|c|}
\hline & $\begin{array}{c}\text { Total Scan } \\
\text { Area } S_{1}\left(\mathrm{~mm}^{2}\right)\end{array}$ & $\begin{array}{l}\text { Number of } \\
\text { Microscopic } \\
\text { Inclusions }\end{array}$ & $\begin{array}{c}\text { Number of Microscopic } \\
\text { Inclusions per Unit } \\
\text { Area }\left(/ \mathrm{mm}^{2}\right)\end{array}$ & $\begin{array}{c}\text { Total Area of } \\
\text { Microscopic Inclusions } \\
\mathrm{S}_{2}\left(\mathrm{~mm}^{2}\right)\end{array}$ & $\mathrm{S}_{2} / \mathrm{S}_{1}(\%)$ \\
\hline Normal (without Mg) & 35.4 & 2042 & 57.7 & 0.023 & 0.065 \\
\hline Experiment (with Mg) & 30.0 & 2211 & 73.7 & 0.017 & 0.057 \\
\hline
\end{tabular}

As the results show in Table 5, for the shipbuilding steel in this research, the number of the microscopic inclusions per unit area was increased, and the total area of microscopic inclusions was decreased, as compared with the normal shipbuilding steel without $\mathrm{Mg}$. It showed that, with $\mathrm{Mg}$ added, the inclusions had been refined effectively.

The oxide metallurgy effect for the different size inclusions is closely related to the metallographic structure of the steel plate. From the previous studies of the authors, in the as-cast condition, the IAF had been induced by the inclusions mainly with the size of $10 \mu \mathrm{m}$, and inclusions in the range of $15-20 \mu \mathrm{m}$ could also be used as the core to induce the IAF, but for the rolled plate with smaller grain size, the IAF could only be induced by the smaller inclusions.

The typical morphologies of IAF and its inducing cores (inclusions) were shown in Figure 9. It is shown that, these inclusions were substantially spherical and their size were mostly about $3 \mu \mathrm{m}$. 
In order to further analyze the composition of inclusions, in this study, scanning electron microscopy and energy spectroscopy were used to perform surface scan analysis of inclusions. The representative inclusion surface scans are shown in Figures 10 and 11, respectively. In this study, the five elements of $\mathrm{Mg}, \mathrm{Al}, \mathrm{Mn}, \mathrm{Ti}$ and S that have an important influence on the induction of IAF were mainly investigated.

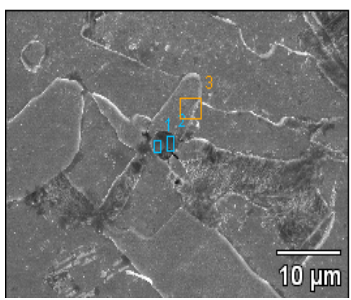

(a)

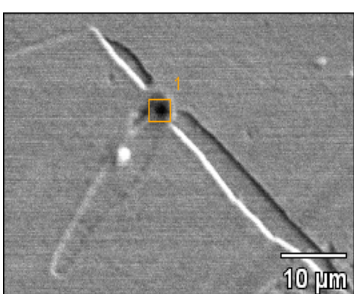

(b)

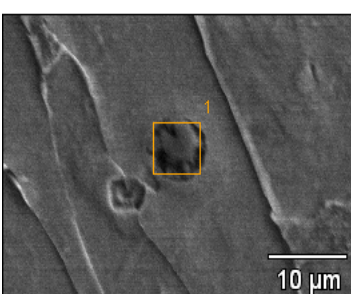

(c)

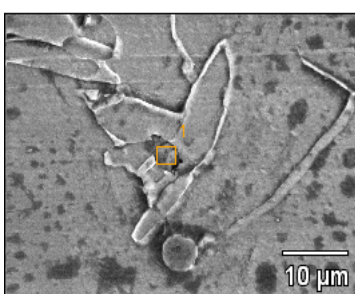

(d)

Figure 9. Typical characters of the inclusions which induced intragranular acicular ferrite (IAF). (a), inclusion size is about $2.5 \mu \mathrm{m}$; (b), inclusion size is about $3.0 \mu \mathrm{m}$; (c), inclusion size is about $7.0 \mu \mathrm{m}$; (d), inclusion size is about $3.3 \mu \mathrm{m}$.
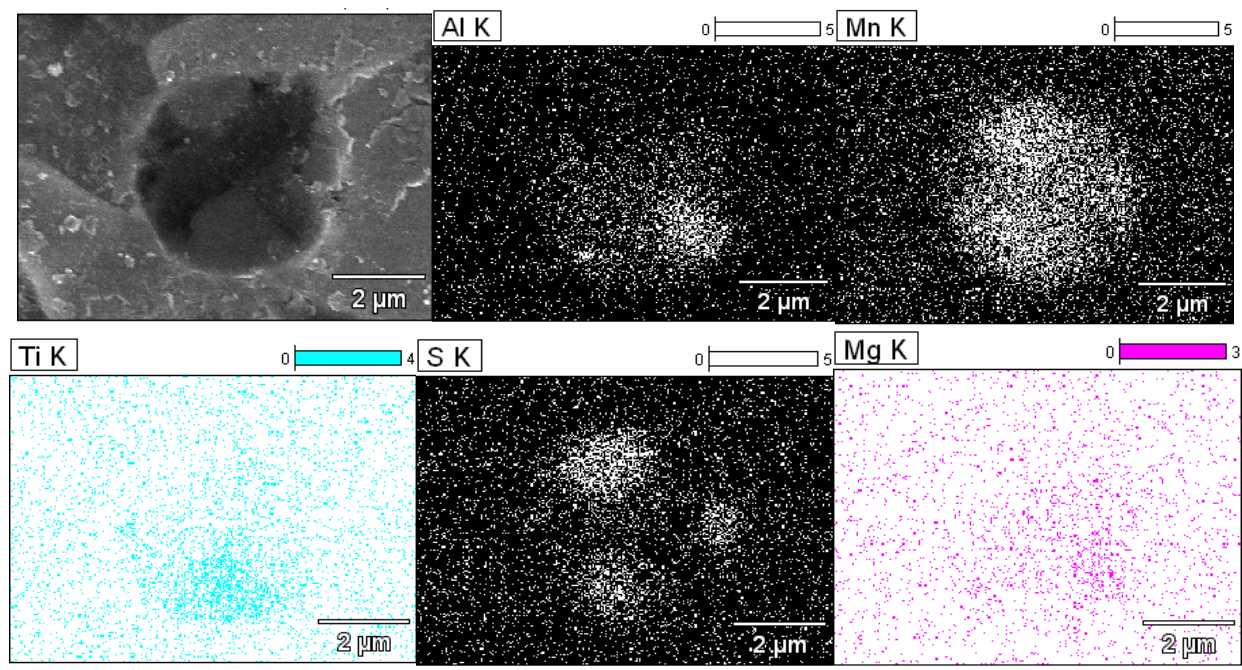

Figure 10. Surface scanning analysis of inclusions that contain $\mathrm{Mg}$.

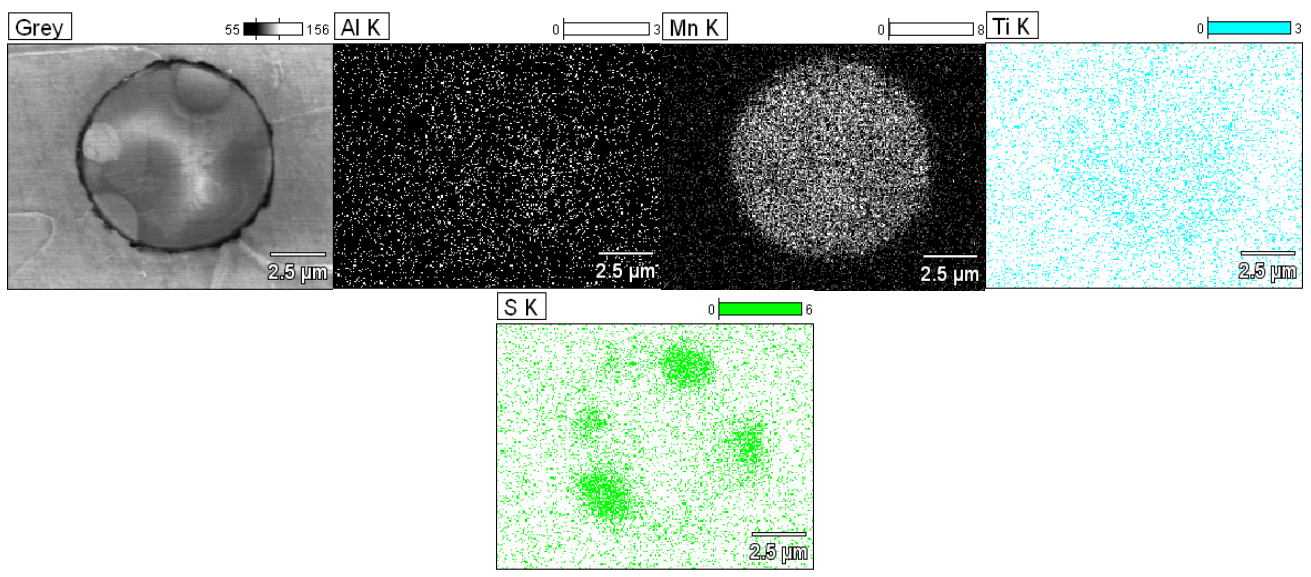

Figure 11. Surface scanning analysis of inclusions that free from $\mathrm{Mg}$.

Figure 10 is a typical surface scan of Mg-containing inclusions that induced IAF. As shown in Figure 10, the size of the inclusion was 3-4 $\mathrm{mm}$, corresponding to the inclusion in Figure $9 \mathrm{~b}$. For the 
five elements examined, the Mg elements were basically diffusely distributed; the Mn element was substantially full of inclusions, but was more concentrated at three positions; the Al and Ti elements were relatively more concentrated in the lower half; the $S$ elements were concentrated in the inclusions at three points on the periphery.

As shown in Figure 9b, the inclusions induced a total of three acicular ferrite branches, and the three branches correspond to the three points in S. Under normal conditions, $S$ existed in the form of $\mathrm{MnS}$, and the concentration of S and Mn causes the decrease of the Mn content in the surrounding area, which in turn induces acicular ferrite.

Figure 11 is a typical surface scan of Mg-free inclusion that induced IAF. As shown in Figure 11, the size of the inclusion was about $7 \mu \mathrm{m}$, corresponding to the inclusion in Figure 9c. Among the elements examined, the Mn element was substantially filled with the entire inclusion; $\mathrm{Al}$ and $\mathrm{Ti}$ elements were basically dispersed; S element was concentrated on the four points of the periphery of the inclusion and appeared in the other two areas on the periphery of the inclusion.

As shown in Figure 9c, the inclusion was within an elongated IAF, the width of which exceeded $10 \mu \mathrm{m}$. Although it also induced acicular ferrite, due to the relative thickness of the tissue, its performance was inferior to that of the IAF induced by the inclusions shown in Figure 10.

From the comparison of Figures 10 and 11, it could be found that although $\mathrm{Mg}$ element is not the primary cause for the IAF inducing, Mg can effectively reduce the size of inclusions, and thus increase the inclusion ability of IAF inducing; so for the steel in this research, $\mathrm{Mg}$ is essential.

\section{Conclusions}

(1) The HAZ of three kinds of thickness plates induced much IAF; with Mg addition, the inclusion dimension had been reduced effectively, and the IAF induced ability of the inclusions had also been improved. If the original metallographic microstructure of steel was coarse, the pinning effect of the inclusions would be reduced significantly, and the microstructure of HAZ would be coarsened and the impact toughness of HAZ would be decreased, so there is a certain matching relationship between the metallographic microstructure and the inclusion dimension.

(2) $\mathrm{Mg}$ is not the primary cause of the IAF inducing, but $\mathrm{Mg}$ can effectively reduce the size of inclusions, and thus increase the inclusion ability of IAF inducing.

(3) The difference of HAZ impact toughness with different welding heat input and different impact temperature is significant; considering the influence of welding heat input and metallographic microstructure on the impact toughness of HAZ, the welding heat load had a far greater effect than the metallographic microstructure on the ductile-brittle transition temperature.

Author Contributions: Conceptualization, L.-g.S.; Funding acquisition, L.-g.Z. and L.-g.S.; Software, Y.-s.L.; Supervision, Y.-g.L. and L.-g.S.; Writing—review \& editing, H.-r.L.

Funding: This research was funded by National Natural Science Foundation of China, grant number 51474089, and by Natural Science Foundation of Hebei Province, grant number E2017209194.

Acknowledgments: We would like to extend my sincere gratitude to Professor Wang Shuoming and Professor Liu Zengxun, for their instructive advice and useful suggestions on the thesis. We also thanks the engineers in Handan steel company, they provided a lot for the industrial experiment.

Conflicts of Interest: The authors declare no conflict of interest.

\section{References}

1. Takamura, J.; Mizoguchi, S. Role of oxides in steels perform ances metallurgy of oxides in steels. In Proceedings of the ISIJ Sixth International Iron and Steel Congress, Nagoya, Japan, 21-26 October 1990; pp. 591-597.

2. Mizoguchi, S.; Takamura, J. Control of oxides as inoculants metallurgy of oxides in steels. In Proceedings of the ISIJ Sixth International Iron and Steel Congress, Nagoya, Japan, 21-26 October 1990; pp. 598-604.

3. Hitoshi, H. Effect of Ti and alloying elements on microstructure and toughness of simulated HAZ of $780 \mathrm{MPa}$ class steels. Tetsu-to-Hagane 2004, 90, 271-277. 
4. Shu, W.; Wang, X.; Li, S.; He, X. Nucleation and growth of intragranular acicular ferrite and its effect on grain refinement of the heat-affected-zone. Acta Metall. Sin. 2011, 47, 435-441.

5. Hong, S.G.; Kang, K.J.; Park, C.G. Strain-induced precipitation of $\mathrm{NbC}$ in $\mathrm{Nb}$ and Nb-Ti microalloyed HSLA steels. Scr. Mater. 2002, 46, 163-168. [CrossRef]

6. Vega, M.I.; Medina, S.F.; Quispe, A.; Gomez, M.; Gomez, P.P. Influence of TiN particle precipitation state on static recrystallisation in structural steels. ISIJ Int. 2005, 45, 1878-1886. [CrossRef]

7. Kanazawa, S.; Nakashima, A.; Okamoto, K.; Kanaya, K. Improved toughness of weld fussion zone by fine TiN particles and development of a steel for large heat input welding. Tetsu-to-Hagane 1975, 61, 2589-2603. [CrossRef]

8. Kasamatsu, Y. Effect of titanium and nitrogen on toughness of heat-affected zone of steel plate with tensile strength of $50 \mathrm{~kg} / \mathrm{mm}^{2}$ in high heat input welding. Tetsu-to-Hagane 1979, 65, 1232-1241. [CrossRef]

9. Song, M.; Song, B.; Hu, C.; Xin, W.B.; Song, G.Y. Effect of Ti-Mg complex deoxidation on the microstructure and impact properties of HAZ in steel. Chin. J. Eng. 2015, 37, 883-888.

10. Zhu, K.; Yang, Z. Effect of Mg addition on the ferrite grain boundaries misorientation in HAZ of low carbon steel. J. Mater. Sci. Technol. 2011, 27, 252-256. [CrossRef]

11. Sun, Z.; Huang, J.; Zhang, H.; Zhao, X.; Li, Q. Microstructures and mechanical properties of joints of mi-croalloyed EH40 ship steel with high heat-input welding. Trans. China Weld. Inst. 2008, 29, 42-43.

12. Sohn, S.S.; Hong, S.; Lee, J.; Suh, B.-C.; Kim, S.-K.; Lee, B.-J.; Kim, N.J.; Lee, S. Effects of Mn and Al contents on cryogenic-temperature tensile and Charpy impact properties in four austenitic high-Mn steels. Acta Mater. 2015, 100, 39-52. [CrossRef]

13. Hwang, B.; Lee, C.G. Influence of thermomechanical processing and heat treatments on tensile and Charpy impact properties of B and Cu bearing high-strength low-alloy steels. Mater. Sci. Eng. A 2010, 527, 4341-4346. [CrossRef]

14. You, Y.; Wang, X.; Shang, C. Influence of austenitizing temperature on the microstructure and impact toughness of a high strength low alloy HLSA100 steel. Acta Metall. Sin. 2012, 48, 1290-1298. [CrossRef]

15. Sung, H.K.; Shin, S.Y.; Cha, W.; Oh, K.; Lee, S.; Kim, N.J. Effects of acicular ferrite on charpy impact properties in heat affected zones of oxide-containing API X80 linepipe steels. Mater. Sci. Eng. A 2011, 528, 3350-3357. [CrossRef]

16. Tao, P.; Yu, H.; Fan, Y.; Fu, Y. Effects of cooling method after intercritical heat treatment on microstructural characteristics and mechanical properties of as-cast high-strength low-alloy steel. Mater. Des. 2014, 54, 914-923. [CrossRef]

17. Li, L.; Cao, F.; Wang, Y.; Zhang, X.; Lu, C. Analysis on low temperature impact toughness and fracture morphologies of X90 pipeline steel. Heat Treat. Met. 2015, 40, 190-193.

18. Luo, K.Y.; Wang, C.Y.; Sun, G.F.; Cui, C.Y.; Sheng, J.; Lu, J.Z. Investigation and microstructural analyses of massive LSP impacts with coverage area on crack initiation location and tensile properties of AM50 magnesium alloy. Mater. Sci. Eng. A 2016, 650, 110-118. [CrossRef]

19. Chatterjee, A.; Chakrabarti, D.; Moitra, A.; Mitra, R.; Bhaduri, A.K. Effect of deformation temperature on the ductile-brittle transition behavior of a modified 9Cr-1Mo steel. Mater. Sci. Eng. A 2015, 630, 58-70. [CrossRef]

20. Bai, X.; Wu, S.; Liaw, P.K. Influence of thermo-mechanical embrittlement processing on microstructure and mechanical behavior of a pressure vessel steel. Mater. Des. 2016, 89, 759-769. [CrossRef]

21. Nazari, A.; Milani, A.A.; Khalaj, G. Modeling ductile to brittle transition temperature of functionally graded steels by ANFIS. Appl. Math. Model. 2012, 36, 3903-3915. [CrossRef]

22. Chen, X.M.; Song, S.H.; Weng, L.Q.; Liu, S.J.; Wang, K. Relation of ductile-to-brittle transition temperature to phosphorus grain boundary segregation for a Ti-stabilized interstitial free steel. Mater. Sci. Eng. A 2011, 528, 8299-8304. [CrossRef]

23. Kumar, S.; Nath, S.K. Effect of heat input on impact toughness in transition temperatureregion of weld CGHAZ of a HY 85 steel. J. Mater. Proc. Technol. 2016, 236, 216-224. [CrossRef]

24. Goto, H.; Miyazawa, K.; Yamaguchi, K.; Ogibayashi, S.; Tanaka, K. Effect of cooling rate on oxide precipitation during solidification of low carbon steels. ISIJ Int. 1994, 34, 414-419. [CrossRef]

25. Goto, H.; Miyazawa, K.; Tanaka, K. Effect of oxygen Content on size distribution of oxides in steel. ISIJ Int. 1995, 35, 286-291. [CrossRef] 
26. Shen, D.; Yuan, Z. Factors influencing the DBTT of 2.25CrMo steel. J. Wuhan Univ. Sci. Technol. 2011, 34, 410-413.

27. Yang, L.; Liu, J.; Bao, Y. Researches on X70 cleanliness in refine and continuous casting process. J. Univ. Sci. Technol. Beijing 2007, 29, 97-100.

28. Li, C.; Bao, Y.; Liu, J. Investigation of reasonable cleanliness for high-grade linepipe steel scale production. J. Univ. Sci. Technol. Beijing 2007, 29, 10-13. 